Doi: $10.32481 / \mathrm{djph} .2021 .09 .011$

\title{
Dementia Care in Delaware:
}

\section{The Role of Long-Term Care Resources}

\author{
Cheryl Heiks
}

\section{Executive Director, Delaware Health Care Facilities Association}

Delaware has over 80 long-term care providers, including skilled nursing, intermediate care, and assisted living facilities. That number is growing. The state is fortunate to have providers specializing in pediatric care and others caring solely for individuals with intellectual and developmental disabilities. Skilled nursing facilities, staffed by licensed healthcare professionals, provide post-acute care including specialized therapies, medications, and medical equipment. Assisted living facilities (ALF) designed to provide personalized assistance with activities of daily living are state-licensed and increasing across the country. Some ALFs specialize in care for individuals with memory issues. Assisted living services can be provided in stand-alone buildings or in a separate wing of a larger facility offering additional types of care. Residents in assisted living maintain contact with their primary care physicians and medical specialists.

In Delaware, an additional level of care is available, providing flexibility for residents and families. Intermediate nursing care provides regular nursing care to residents who do not require hospitalization or skilled nursing care but need services above the level of room and board. Delaware's providers are a unique mix of non-profit and for-profit, regional leaders and single building facilities; some are family-owned. Many of the providers have long histories of caring for the elderly and disadvantaged. Nationwide, approximately $60 \%$ of nursing home residents rely on Medicaid to help pay for their care. The long-term care industry is highly regulated, and there are numerous state and federal rules about what long-term-care providers can and cannot do.

The American Geriatrics Society estimates that individuals with some form of dementia constitute $47.8 \%$ of nursing home populations in the United States. Delaware's long-term care and senior living community serves people with dementia throughout the state. Dementia has many causes, including Parkinson's, Alzheimer's, Creutzfeldt-Jakob disease, and others. All these diseases cause deterioration in the brain and on an individual's reasoning abilities, impacting their quality of life and can keep them from living safely independently. Although associated with seniors, other types of brain destruction can cause dementia, including head injury, stroke, and brain tumors. People with Alzheimer's Disease and other forms of dementia are four times more likely to need to spend time in a skilled nursing facility. Within the variety of post-acute options available, over two-thirds of Delaware's long-term care providers provide some level of memory or dementia care services.

Long-term care providers committed to providing care for older adults with dementia can improve the quality of life for these residents by offering services difficult to duplicate in other settings. The Journal of the American Medical Directors Association published a 2021 study, ${ }^{1}$ showing that residents with Alzheimer's Disease and other dementias in nursing homes with Alzheimer's units, higher licensed nurse staffing, and in more competitive markets with access to non-profit facilities had better end-of-life care/outcomes. Modifications to state Medicaid nursing home payments and other forms of reimbursement may promote better end-of-life care/outcomes for this population. A 2018 study demonstrated improved quality of care factors 
for individuals who receive treatment in facilities with special care units for residents with dementia. ${ }^{2}$ Continued research and resources to understand and subsequent investments in what works is needed for residents with ADRD, regardless of their senior living environment.

In addition to those older adults with neurocognitive disorders, long-term care providers serve the needs of older adults with a range of psychosocial conditions including severe mental illness, substance use disorders, and homelessness. ${ }^{3}$ According to a 2019 national study published in the Journal of the American Geriatrics Society, ${ }^{4}$ behavioral health disorders affect $65 \%$ to $90 \%$ of nursing home residents. The care of this population presents growing challenges to long-term care providers because of their special treatment needs, which include specialized behavioral interventions as well as medications known to carry increased risk when used in older individuals. The American Health Care Association/National Center for Assisted Living provides links to CARES ("Connect with the Person, Assess Behavior, Respond Appropriately, Evaluate What Works, and Share with Others") training, an approach for long-term care providers which emphasizes the reduction of off-label use of antipsychotics and promotes the implementation of additional care strategies for those individuals with serious mental illness. ${ }^{5}$ CARES training provides education on schizophrenia, bipolar disorder, schizoaffective disorder, major depression, PTSD, borderline personality, psychotic disorders, and dementia. The CARES training is only one educational program; long-term care and the general healthcare industry need additional resources.

An additional special challenge faced by long term care providers is the recognition of behavioral changes resulting from acute, treatable medical conditions. Ongoing healthcare assessment by trained nurses and counselors is essential to prevent and treat such conditions in individuals residing either temporarily or long-term in communal living settings. The importance of nurses, physician assistants, and physicians who are familiar with the resident and have up-todate access to their prior medical history, medication information, and any recent changes in their status remains an important key to quality care. For those individuals who reside in senior living environments and receive care from private health care providers, maintaining effective communication and keeping an accurate, current record of any changes in medication and medical diagnoses is essential to maintaining quality care. Technological advances have made it easier to share medical information between providers, when approved; to avoid duplicative tests; to reduce unnecessary health care costs; and to ensure all health care records stay as current as possible. A resident who receives care in a hospital or a surgery center, for example, needs their long-term care providers to have access to tests done in those settings. Those results contribute to good care and may prove critical in the event of a health emergency.

Delaware, like other states in the US, is experiencing an increase in the older population and an increase in the number of older adults in need of long-term residential care. By 2040, the number of Delawareans aged 60 and older will make up nearly 34\% of the State's population. Projections show that by 2040 , the "oldest old" (age 85 and older) population will grow $171.6 \%{ }^{6}$ The growth of our older population will necessitate greater availability of competent care for people with dementia and behavioral health conditions. It will be necessary to increase the number of behaviorally trained staff including psychiatric consultants and to improve access to more community providers. The increased cost of providing care suggests the need for reviewing reimbursement of care. States with aging populations require targeted investments in workforce development strategies to recruit and retain long-term care specialists, behavioral health consultants and medical professionals interested in geriatric care. 
Doi: $10.32481 / \mathrm{djph} .2021 .09 .011$

\section{References}

1. Orth, J., Li, Y., Simning, A., Zimmerman, S., \& Temkin-Greener, H. (2021, February). Endof-Life care among nursing home residents with dementia varies by nursing home and market characteristics. Journal of the American Medical Directors Association, 22(2), 320328.e4. PubMed https://doi.org/10.1016/j.jamda.2020.06.021

2. Joyce, N. R., McGuire, T. G., Bartels, S. J., Mitchell, S. L., \& Grabowski, D. C. (2018, October). The impact of dementia special care units on quality of care: An instrumental variables analysis. Health Services Research, 53(5), 3657-3679. PubMed https://doi.org/10.1111/1475-6773.12867

3. Orth, J., Li, Y., Simning, A., \& Temkin-Greener, H. (2019, August). Providing behavioral health services in nursing homes is difficult: Findings from a national survey. Journal of the American Geriatrics Society, 67(8), 1713-1717. PubMed https://doi.org/10.1111/jgs.16017

4. American Geriatrics Society. (2020). American Geriatrics Society Policy Brief: COVID-19 and nursing homes. Retrieved from https://agsjournals.onlinelibrary.wiley.com/doi/epdf/10.1111/jgs.16477

5. Maust, D. T., Kim, H. M., Chiang, C., \& Kales, H. C. (2018, May 1). Association of the centers for Medicare \& Medicaid services' national partnership to improve dementia care with the use of antipsychotics and other psychotropics in long-term care in the United States from 2009 to 2014. JAMA Internal Medicine, 178(5), 640-647. PubMed https://doi.org/10.1001/jamainternmed.2018.0379

6. Delaware Health Resources Board. (2020, Oct). 2019 Delaware nursing home \& 2019 assisted living utilization reports: 2020-2025 Delaware nursing home bed projections. Retrieved from https://dhss.delaware.gov/dhss/dhcc/hrb/files/nhalrptsbedproj2019_102220.pdf

Copyright (c) 2021 Delaware Academy of Medicine / Delaware Public Health Association.

This is an Open Access article distributed under the terms of the Creative Commons Attribution Non-Commercial License (https://creativecommons.org/licenses/by-nc-nd/4.0/) which permits unrestricted non-commercial use, distribution, and reproduction in any medium, provided the original work is properly cited. 